\title{
EDITORIAL
}

\section{Hypsarhythmia or Hypsarrhythmia?}

John J. Millichap $\mathrm{MD}^{1 *}$ iD and J. Gordon Millichap, MD ${ }^{1}$ iD

${ }^{I}$ Division of Neurology, Ann \& Robert H. Lurie Children's Hospital of Chicago, Chicago, I; and

Departments of Pediatrics and Neurology, Northwestern University Feinberg School of Medicine, Chicago, IL

*Correspondence: DrJohn J. Millichap, E-mail: j-millichap@northwestern.edu

Keywords: EEG; Epilepsy; Infantile Spasms

Hypsarhythmia was originally spelled with one ' $r$ ' by Drs Frederick and Erna Gibbs when they coined the term in 1952 [1]. They wished to emphasize that "the term applied to a specific type of electroencephalographic abnormality", and preferred the specific one ' $r$ ' spelling to avoid confusion with a literal translation of the two ' $r$ ' Greek root, "mountainous arrhythmia" [2,3]. The one ' $r$ ' spelling was the rule in the 1950s-60s [4]. The two ' $r$ ' spelling eventually became convention in the literature by the mid-1970s (Figure 1).

Although the Editor of Pediatric Neurology Briefs prefers the single ' $r$ ' spelling in deference to Dr Gibbs, the intended meaning is accepted for both spellings today.

\section{References}

1. Gibbs FA, Gibbs EL. Atlas of Electroencephalography. Volume 2. Reading (MA): Addison-Wesley; 1952. http://www.worldcat.org/oclc/ 768435492

2. Gibbs FA. Infantile Spasms and Hypsarrhythmia or Hypsarhythmia. Dev Med Child Neurol 1965 Jun;7(3):329. http://dx.doi.org/10.1111/j.14698749.1965.tb10947.x PMID:14343238

3. MacKeith R. Infantile Spasms and Hypsarrhythmia or Hypsarhythmia. Dev Med Child Neurol 1965 Apr;7(2):204. http://dx.doi.org/ 10.1111/j.1469-8749.1965.tb10916.x PMID:14317541

4. Millichap JG, Bickford RG. Infantile Spasms, Hypsarhythmia, and Mental Retardation. JAMA 1962;182(5):523-527. http://dx.doi.org/ 10.1001/jama.1962.03050440015004.

\section{Disclosures}

The author(s) have declared that no competing interests exist.

Figure 1. Google Ngram Viewer: Book text search for case-insensitive 'Hypsarrhythmia' (blue line) and 'Hypsarhythmia' (red line) from 1950-2008 in English. [Cited August 31 2015.] Available from: https://goo.gl/sJI1uG

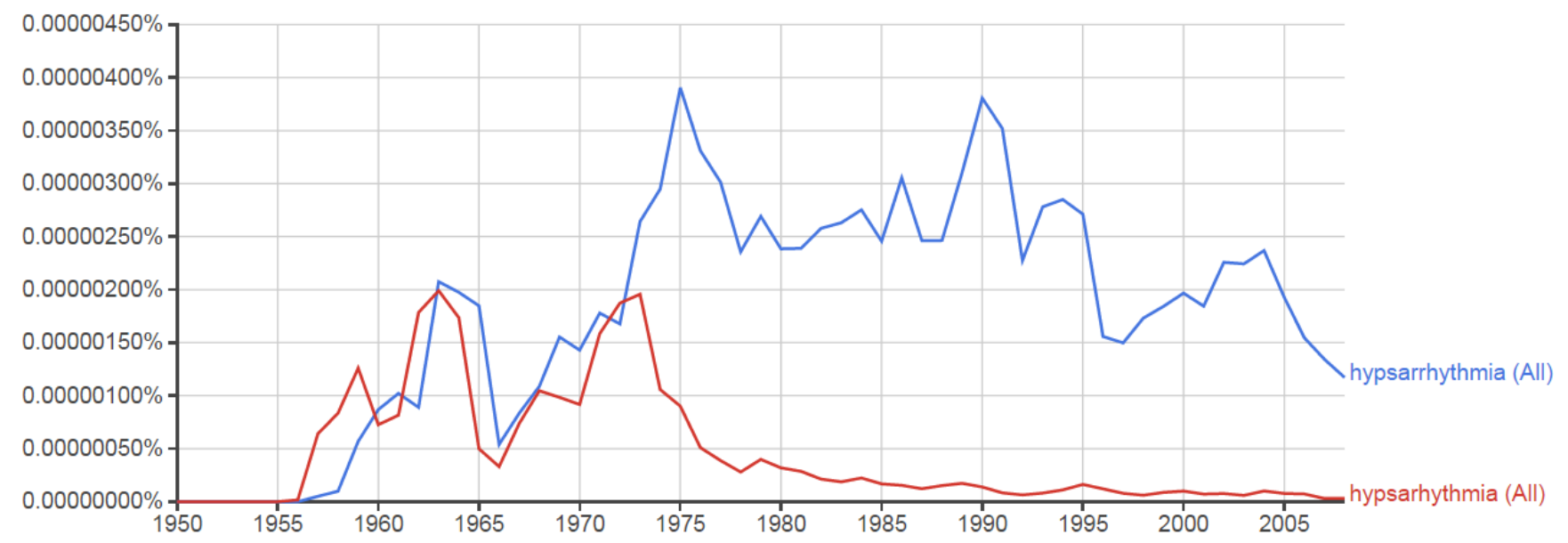

Pediatric Neurology Briefs 2015;29(8):64. http://dx.doi.org/10.15844/pedneurbriefs-29-8-7.

ISSN: 1043-3155 (print) 2166-6482 (online). Received 2015 Aug 25. Accepted 2015 Aug 28. Published 2015 Sep 7.

(c) BY (C2015 The Author(s). This work is licensed under a Creative Commons Attribution 4.0 International License. 